\title{
Fire Resistance of Unprotected Ultra Shallow Floor Beams (USFB): A Numerical Investigation
}

\author{
C. Maraveas*, School of Mechanical, Aerospace and Civil Engineering, \\ University of Manchester, Manchester, UK \\ K. D. Tsavdaridis, School of Civil Engineering, University of Leeds, Leeds, UK \\ A. Nadjai, School of Build Environment, Ulster University, Londonderry, UK
}

Received: 14 December 2014/Accepted: 7 November 2015

\begin{abstract}
This paper presents the fire resistance behaviour of partially encased in concrete ultra shallow floor beams (USFB) using numerical analysis method based on material specifications of the EN1994-1-2. Investigating the behaviour of USFBs under elevated temperatures is crucial in determining their fire resistance and evaluating their overall performance in contemporary construction. Even though the manufacturing company provides fire resistances for USFBs based on EC4-1-2 procedures, their response to elevated temperature effects remains up to date neither well documented nor clearly understood. The analyses involved two different beams of span $5 \mathrm{~m}$ and $8 \mathrm{~m}$ respectively, as specified by the manufacturer. Analysis results showed that such beams, when unprotected, experience severe temperature gradients if exposed to fire, as the lower flange still remains unprotected in contrast to the concrete encased part of the cross-section. As it was anticipated, the moment capacity governs the fire resistance of the beams and the load factor highly effects the elevated temperature behaviour. In addition, the loss of the lower flange, which develops high temperatures, is not compensated by the web and consequently the moment capacity ultimately depends on the temperature of the lower flange. Results also suggest that simulated beams sustained the applied load for approximately $40 \mathrm{~min}$ of exposure to the standard fire.
\end{abstract}

Keywords: Ultra shallow floor beams, Fire resistance, Composite, Flooring systems, Moment capacity, Shear capacity

\section{Introduction}

Various shallow floor systems have been developed recently. The most commonly encountered in the industry are the "slim floor" and the "slim deck" systems. Several companies have developed their own systems, such as the ultra shallow floor beam (USFB) composite deck system [1]. The behaviour of such flooring systems when exposed to fire is generally satisfactory, because the encasing (plug) concrete acts as thermal insulation, even though the lower flange is unprotected. The

\footnotetext{
* Correspondence should be addressed to: C. Maraveas, E-mail: c.maraveas@maraveas.gr
} 
results of relevant parametric analyses [2-4] have shown that the fire resistance of such shallow systems is governed by deflection, as they experience bowing resulting from considerable thermal gradients.

In spite of the fact that the fire behaviour of slim floor and slim deck systems has been investigated by various researchers [2, 5-10], systems proposed by other manufacturing companies, such as the USFBs [1], have not been sufficiently studied at elevated temperatures. The USFBs seem to exhibit significantly different behaviour than the aforementioned systems (which generally have a satisfactory fire resistance) as they use shallow sections which are protected less by the concrete [2] while the web, which has to develop stresses after the capacity loss of the lower flange, in order to develop a moment capacity, is perforated. The manufacturing company though certifies (based on EC4-1-2 [12] procedures) for each beam the appropriate fire insulation. Due to the absence of vital information for evaluating the Eurocodes procedures for the specific system and the fact that experimental results are not available, the authors conducted a numerical simulation of such USFB systems exposed to fire. For this purpose, finite element (FE) analyses with the commercial program ABAQUS were carried out. The methodology used in the current USFB analysis is similar to the model used in the analysis of asymmetric slim floor beams in fire presented by Maraveas et al. [2].

Two commonly used simply supported isolated USFBs have been analysed. The considered span lengths are $5 \mathrm{~m}$ and $8 \mathrm{~m}$, with shape and arrangement as described in Section 2. Additional checks were made to determine the performance of the section in fire and ensure that the serviceability limit state stresses were not excessive as evaluated by the manufacturer's software [1]. Table 1 synopsises the normal temperature maximum design unity factors and the critical load combination for the two considered beams. The calculations performed with the use of the software Cellbeam v9.0 (certified by the Steel Construction Institute). The bold values in Table 1 refer to the critical code checks/verifications according to a modified EC4 design procedure proposed by the SCI and used internally by ASD Westok (RT1371).

\section{Table 1 \\ Normal Temperature Maximum Design Unity Factors for the Critical Load Combination}

\begin{tabular}{lcr}
\hline Failure mode & Beam A & Beam B \\
\hline Vertical shear & 0.51 & 0.41 \\
Horizontal shear & 0.98 & 0.76 \\
Moment shear interaction & $\mathbf{1 . 0 0}$ & 0.91 \\
Vierendeel bending & $\mathbf{1 . 0 0}$ & 0.91 \\
Longitudinal shear in slab & 0.16 & 0.14 \\
Vibration (Hz) & 5.49 & $\mathbf{3 . 2 7}$ \\
Imposed deflection (mm) & 8.18 & 19.03 \\
\hline
\end{tabular}




\section{USFB System}

For conventional composite floor beams or down-stand composite beams, the thickness of the flanges increases with the increase in span. Consequently, the steel sections are often heavier than needed. The USFB is a new type of composite floor beam, which is fabricated by welding two highly asymmetric cellular tee-sections together along the web. Profiled steel decking or pre-cast concrete floor units sit on the wider bottom flange, as shown in Figures 1 and 2. The top and bottom tee-sections are cut from different parent plain beams where the top tee-section is smaller than the bottom tee-section. This asymmetric beam section property reduces the self-weight while increases the moment capacity.

USFB provides superior structural performance [13] due to the concrete infill where the ultimate vertical load carrying capacity of the USFB can increase by up to $108 \%$ compared to the corresponding non-composite perforated steel beam. Moreover, the shear resistance of the USFB, without using any mechanical shear connectors, such as shear studs, re-bars and ducting [14] can be provided mainly by contributions from the concrete confinement and the steel flange thickness. The strut action of the concrete confinement through certain web openings reduces the Vierendeel bending effects and improves the vertical shear transfer in the vicinity of the web openings. In addition, it has been demonstrated that there is some residual strength in the concrete preventing the local buckling of the perforated steel beams and the load carrying capacity is somewhat higher than that on the non-composite beam.
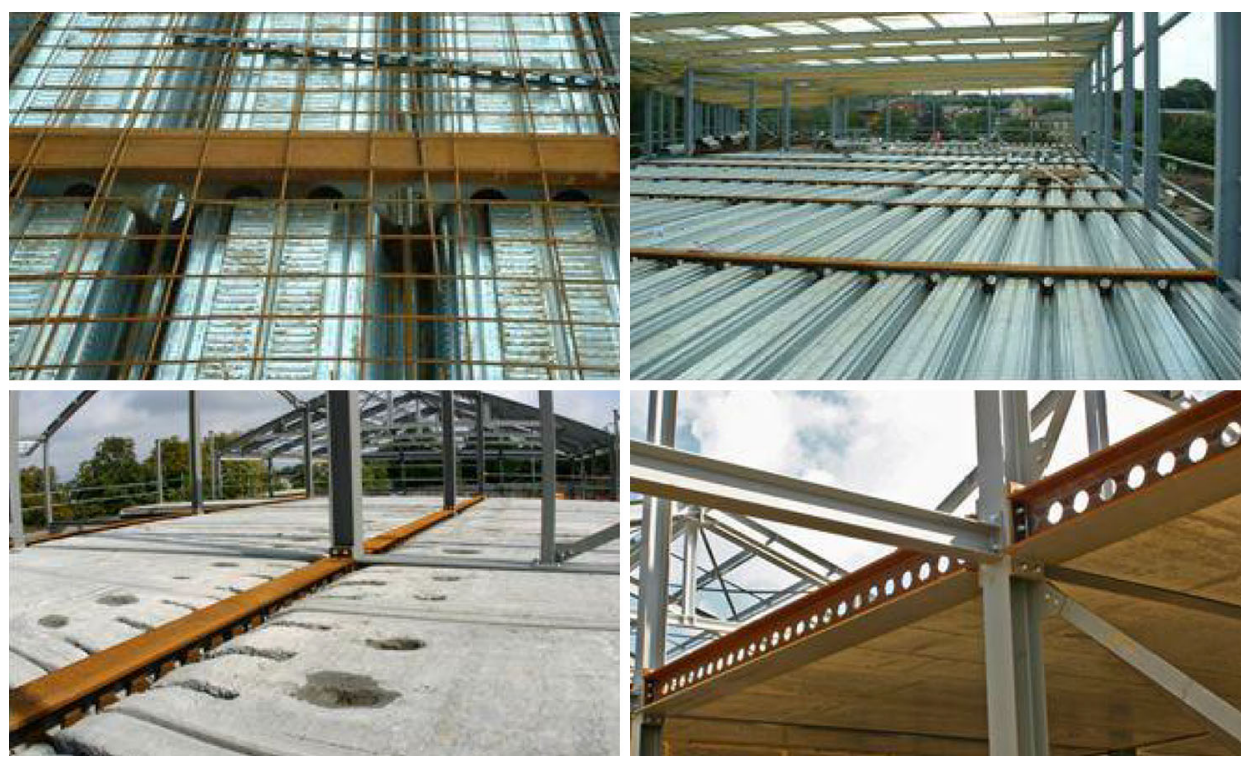

Figure 1. USFB used with profiled steel decking (fop) and with precast concrete unit (botfom) [ 13 ]. 


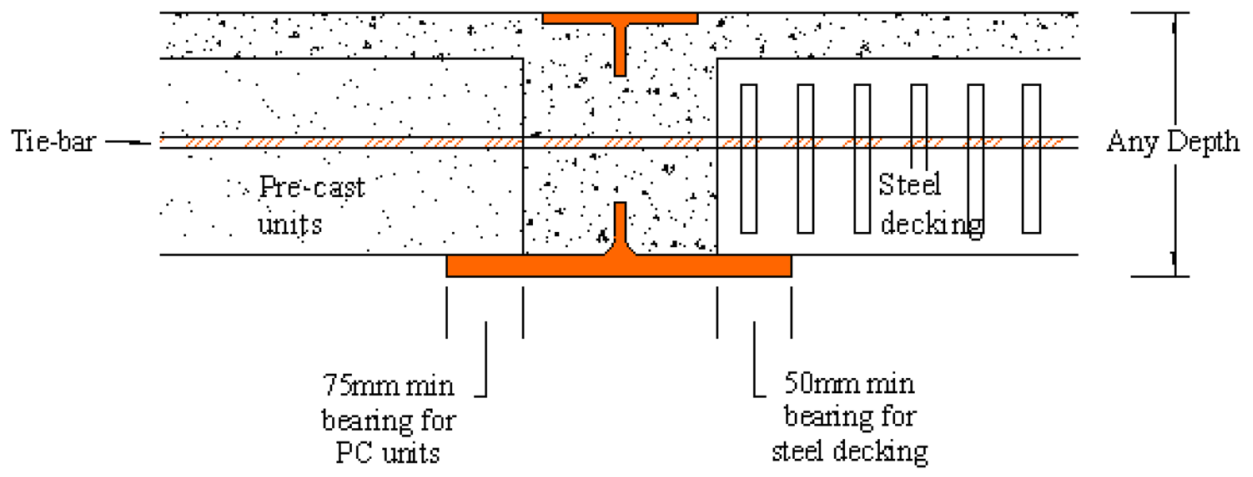

\section{Figure 2. Schematic representation of the USFB (example with the tie-bar shear connector) [ 14 ].}

The circular or elongated web openings provide a channel for reinforcing tiebars, building services and ducting through the structural depth of the beam, thus minimizing the overall floor depth [14]. Transverse to the web reinforcing tie-bars can provide longitudinal shear strength by tying the concrete plugs on both sides of the web. Shear studs can be also used, welded horizontally on the web of the steel beams. Full service integration can be achieved when deep profiled steel decking is employed, as pipes or ducks pass through between the ribs of the steel decking, and typically every a few web openings below the metal deck and concrete slab. As the floors are cast, the in-situ concrete passes through most web openings, which may or may not include a tie-bar or duct. In the case of ultrashallow pre-cast units, all web openings are filled by in-situ concrete, hence service integration cannot be provided, as opposed to the profile metal decking use. This concrete plug forms a unique enhanced mechanism for transferring longitudinal shear force along the beam.

The common range of applications for USFBs is for slab depths of 180 to $300 \mathrm{~mm}$, in which the concrete is placed flush with the upper flange. The nature of the choice of UC for the bottom tee-sections and UB for the top tee-sections is that the asymmetry in flange areas can be over 3 to 1. Composite action reduces this effective asymmetry and improves the bending resistance. In practice, the span to depth ratio of USFBs is generally in the range of 25 to 30 , which means that serviceability rather than bending or shear resistance will govern. Another study has been conducted on the derivation of dynamic properties of USFBs through FE modal analysis and experimental verification [15] and [16].

\section{Geometry, Loads and Material Properties}

\subsection{Geometry of Studied Systems and Normal Temperature Design}

In this paper, two typical simply supported USFBs have been analyzed. The first (beam A) (Figure 3a), has a total section height of $220 \mathrm{~mm}$ and the steel section is 
(a)
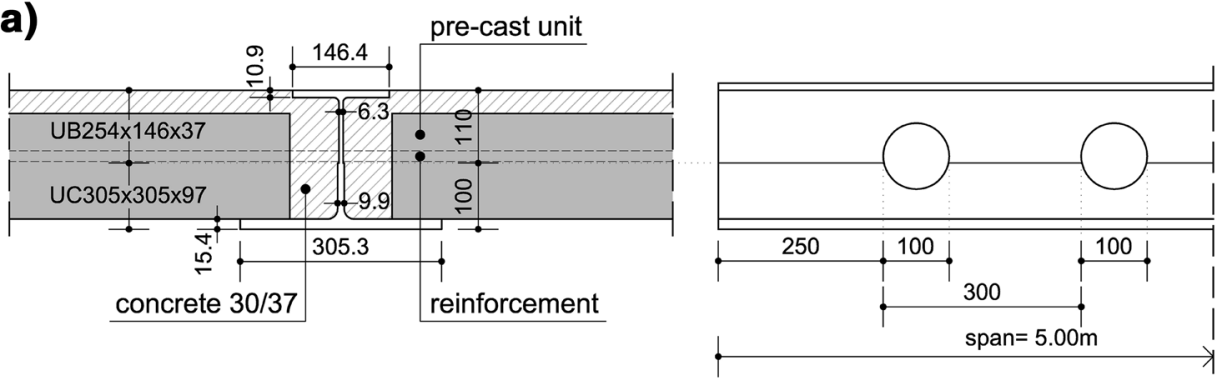

(b)
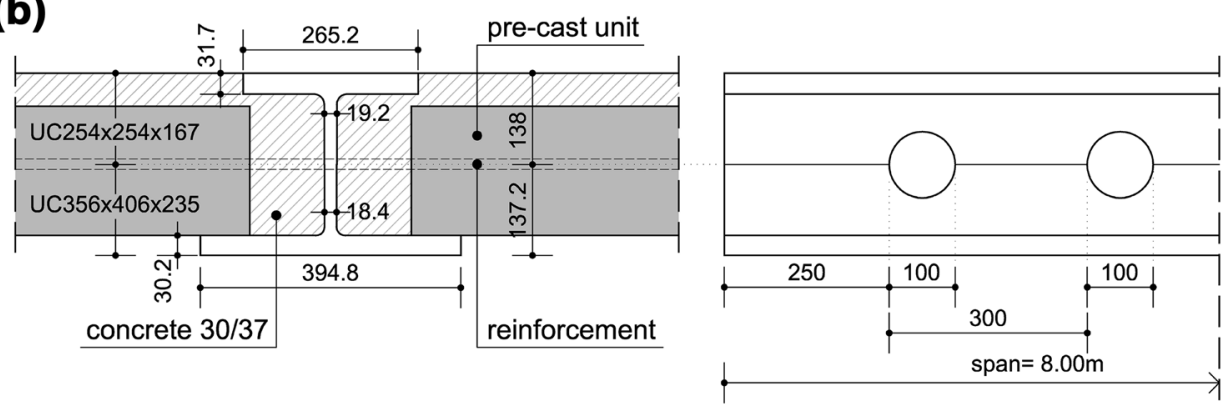

\section{Figure 3. Analyzed beams (a) beam A, and (b) beam B.}

comprised of an upper UB254 $\times 146 \times 37$ tee-section and a lower UC305 $\times 305 \times 97$ tee-section. The second (beam B) (Figure 3b), has a total section height of $275.2 \mathrm{~mm}$ and the steel section is comprised of an upper UC254 $\times 254 \times 167$ tee-section and a lower UC356 $\times 406 \times 235$ tee-section. Both have $100 \mathrm{~mm}$ diameter holes in their web, at an axial distance of $300 \mathrm{~mm}$ between them. The slabs are made of $\mathrm{C} 30 / 37$ concrete and are manufactured with pre-cast units. The span of beam A is $5 \mathrm{~m}$ and of beam B $8 \mathrm{~m}$. The effective width $\left(b_{\text {eff }}\right)$ has been taken equal to $\mathrm{L} / 8$, where $\mathrm{L}$ is the span. The design data at normal temperatures is presented in Table 1. As it is evident, the design is at the limit and there is no over strength that would have affected the results.

\subsection{Applied Loads}

The main load combination for ambient temperature design according to EN1991 [17] is generally:

$$
1.35 \times \text { Permanent }+1.50 \times \text { Imposed }
$$

which gives a total applied force of $332.55 \mathrm{kN}$ for beam A and $452.15 \mathrm{kN}$ for beam B. For fire design, the main load combination according to EN1991 is:

$$
1.0 \times \text { Permanent }+\psi_{2} \times \text { imposed }
$$


where $\psi_{2}$ obtains various values depending on the type of the structure and always $\psi_{2}<1$. As it is not possible to determine the result of the combination with this unknown, it has been assumed that $\psi_{2}=1$. The fire design combination results for these safety factors are approximately $70 \%$ of those of the ambient temperature design combination, which is the maximum load that can be required for fire design. The load is uniformly distributed along the length of each beam.

\subsection{Thermal Properties and Thermal Expansion}

The thermal properties, such as the specific heat and thermal conductivity, of the structural steel and concrete used are given by EC4-1-2 [12]. Especially for the concrete, the upper bound of the curve of thermal conductivity was used. Respectively, the thermal expansion of the two materials was obtained by the same Specification. A density of $7850 \mathrm{~kg} / \mathrm{m}^{3}$ was taken for structural steel, and of $2300 \mathrm{~kg} /$ $\mathrm{m}^{3}$ for concrete.

\subsection{Mechanical Properties}

The mechanical properties of the materials were obtained by the EN1994-1-2 [12]. In particular, the stress-strain temperature diagrams are presented at Figure $4 \mathrm{a}$ for structural steel and at Figure $4 \mathrm{~b}$ and $\mathrm{c}$ for concrete. For reasons of simplicity and given that no effect was noted on the results, the stress-strain temperature relationship of structural steel was used for the reinforcement bars.

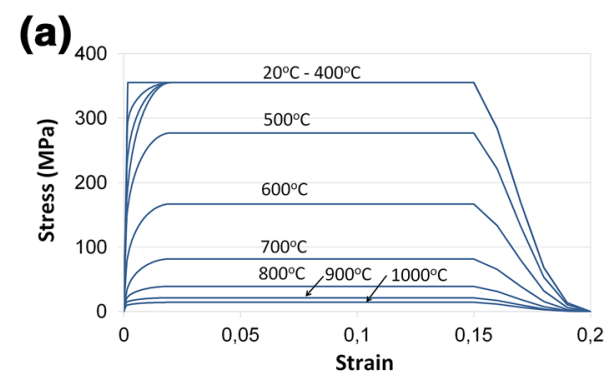

(b)

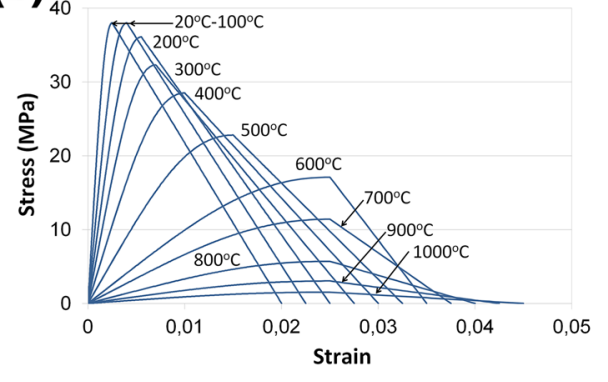

(c)

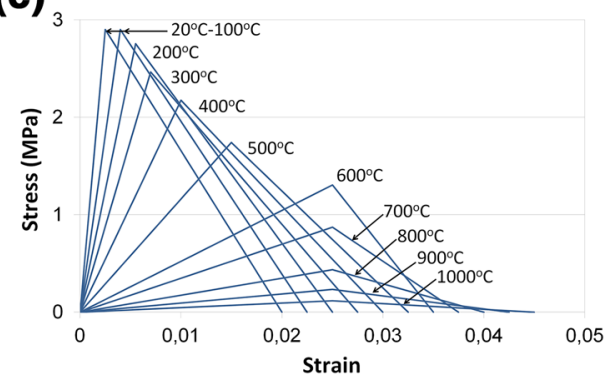

Figure 4. Stress-strain temperature curves of (a) steel and concrete for (b) compression and (c) tension. 


\section{Finite Element (FE) Modelling}

FE modelling of the USFBs is performed with eight-node hexahedral solid elements (Figure 5) taking into consideration the interface between the steel section and the surrounding concrete through appropriate thermal and mechanical contact properties, with the reinforcing bars (shear connection system) modelled as well for estimating the structural response. Due to symmetry, only one quarter of the composite beam is modelled using appropriate boundary and load conditions. The thermal response of the model is calculated via transient uncoupled heat transfer analysis and the structural response via non linear static analysis performed in two steps. In the first step, the composite beam is subjected to static loads at ambient temperature. In the second step, the composite beam is heated using the temperatures predicted by the heat transfer analysis with the previous static loads remaining (transient-state test method).

\subsection{Thermal Analysis}

Three-dimensional (3D) heat transfer elements (DC3D8, 8-node linear bricks) are used for evaluating the thermal response of the USFBs. The temperature distribution in the composite beam is predicted based on the standard fire curve (ISO 834) [18]. A convection coefficient of $25 \mathrm{~W} / \mathrm{m}^{2} \mathrm{~K}$ is assumed for the exposed surface and $9 \mathrm{~W} / \mathrm{m}^{2} \mathrm{~K}$ for the unexposed one. The radiation emissivity for the lower steel flange is taken to be 0.5 and for the concrete floor 0.25 . The heat flow due to radiation is neglected for the upper side. The interface conductivity between concrete and steel is considered as infinite (perfect thermal contact). No heat is transferred normally to the symmetry axis. Heat is applied to the bottom surface of the composite beam and the radiation within the holes of the pre-casted slabs has been considered. Figure 6 presents the thermal analysis boundary conditions.

\subsection{Structural Analysis}

Three-dimensional (3D) solid elements are used for evaluating the structural response of USFB structural systems. The concrete slab is modelled with 8-node
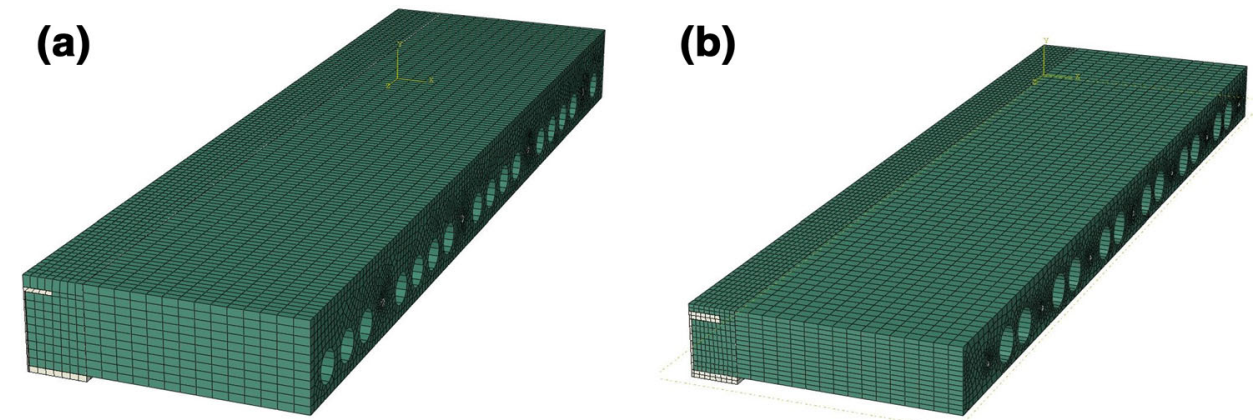

Figure 5. Finite element models of the simulated USFBs (a) beam A, and (b) beam $B$. 


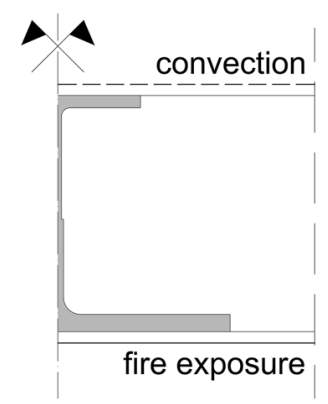

\section{Figure 6. Boundary conditions of thermal analysis model.}

linear brick elements (C3D8) due to numerical instabilities associated with the inelastic behaviour of concrete. On the other hand, the steel beam is modelled with brick elements enhanced with incompatible modes (C3D8I) which provide more accurate results [2]. All the nodes on the symmetry surfaces are prevented to move in the perpendicular direction. Steel nonlinear behaviour is modelled with the von Mises plasticity model, whereas concrete nonlinear behaviour is modelled using the damaged plasticity model in combination with hardening and stiffening options with a dilation angle equal to $55^{\circ}$ (due to numerical reasons that Abaqus' solver was unstable for the concrete dilatation angle between 15 and $30^{\circ}$ ). To solve this stability issue, very small time increments were also employed. It was then resulted that the use of $55^{\circ}$ angle did improve the stability of the analysis without further effects on the analysis results.

Reinforcing bars are modelled employing the *REBAR option in Abaqus [19], while they do not participate in the heat transfer analysis. The interaction between concrete and steel is modelled employing the *CONTACT PAIR option in Abaqus. A friction coefficient equal to 0.50 is considered for the tangential behaviour of the interfaces using the isotropic Coulomb friction model. At final, geometric nonlinearities are considered during the analysis.

\subsection{Validation of FE Models}

The FE models have been validated against slim floor fire tests as presented by Maraveas et al. [2]. The slim floors share common characteristics with the USFBs. Yet, there are a few parts that have not been validated previously, as they do not exist at slim floors, such as:

- The pre-cast slabs; hence it is unknown if the heat transfer model between the steel and the pre-cast concrete is accurate.

- The shear connection system; namely the reinforcement bars that cross through the web openings. 
It is estimated that the above parts of the system do not significantly affect the analyses presented in this paper, and this is because of the organic form of construction (Figures 1,2) indicating how the effective area of concrete is acting with the USFB. Therefore, no substantial slip between steel beam and concrete is expected.

\section{Numerical Results}

\subsection{Thermal Analysis}

The results of thermal the analysis have been presented in Figures 7, 8 and 9. The exposed bottom flange of the steel cross-section develops high temperatures. For beam A, due to low thickness, the temperature is almost uniform except of the area near the web (nodes 1 and 2, Figure 8b), where the temperatures are lower as the web is getting heated. For beam B, the thick bottom flange is heated slowly and the temperature is not uniform (nodes 1 to 6, Figure 9b). The transport of heat on the concrete surface (node 5) is affected by the heat coming from the steel flange at one side and the ISO fire curve at the bottom part. Also, due to the low thermal conductivity of concrete, the temperature at node 5 is higher than the temperature at node 1 (at bottom flange). As the thermal conductivity of steel is high, the web is getting hot too. The temperature at the mid-point of the web exceeds the $400^{\circ} \mathrm{C}$ after $110 \mathrm{~min}$ of exposure (node 2). The upper flange is not practically affected (node 3 ) and it is not exceeding the $120^{\circ} \mathrm{C}$ even after $120 \mathrm{~min}$ of exposure. The temperature of the reinforcement (node 6) is always very low as it is well insulated from the concrete. The insulated by concrete web openings are affecting the temperature distribution. The bottom edge of the opening (node 4) is developing temperatures near the $600^{\circ} \mathrm{C}$ at $60 \mathrm{~min}$ of exposure although the upper edge of the openings is generally experienced low temperatures (Figure 7c). The web openings inside the pre-cast slab demonstrate similar effects (Figure 7b).

\subsection{Structural Analysis}

The results from the structural analysis are presented in Figure 10. It transpires that the limit of $\mathrm{L} / 20$ for the mid-span deflection and deflection rate limit of $\mathrm{L}^{2}$ / (9000d) is exceeded in about $40 \mathrm{~min}$ at both beams. It should be noted that the excess of the deflection rate limit is equivalent to the lost of the load bearing capacity. Both beams also fail in bending at about $40 \mathrm{~min}$ of standard fire exposure. The effect of the load factor is important as the beams may have improved fire resistance for reduced load factors $(\mathrm{R} 60+)$.

From these results it is apparent that fire resistance is governed by the thermal expansion of the lower flange, which develops very high temperatures contrary to the rest of the section. The developing thermal gradients lead to beam bowing and large deflections, which limit the fire resistance. 
(a)
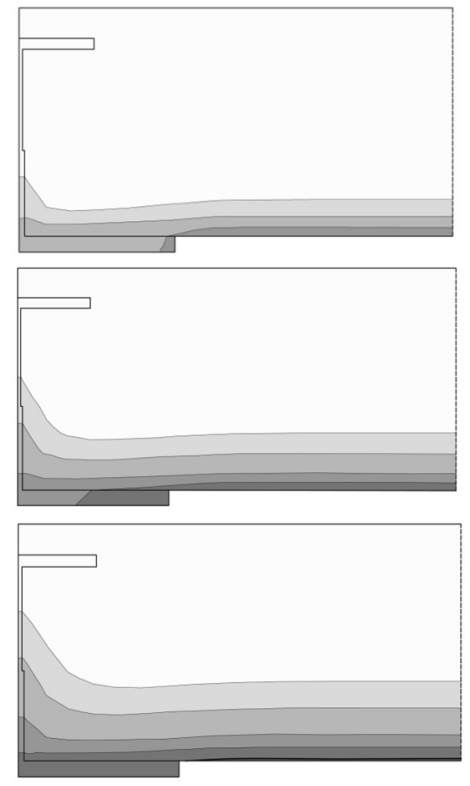

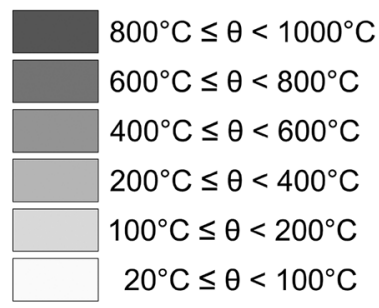

(b)

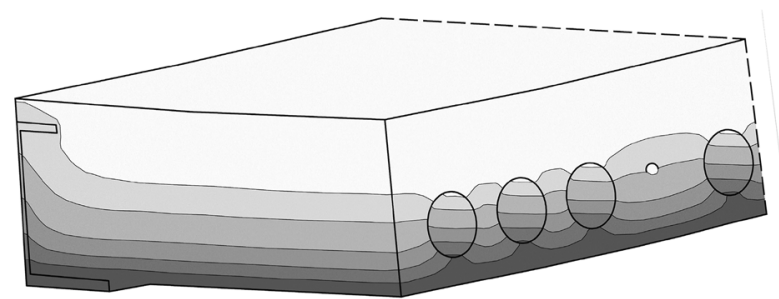

(c)

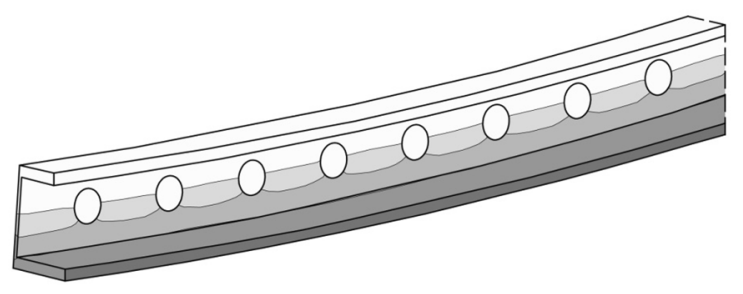

Figure 7. Temperature distribution (a) within the cross-section of beam A for 15, 30 and $45 \mathrm{~min},(b) 3 D$ view for $120 \mathrm{~min}$ of exposure of beam $A$, and (c) temperature distribution within the steel beam (beam B, 30min). 

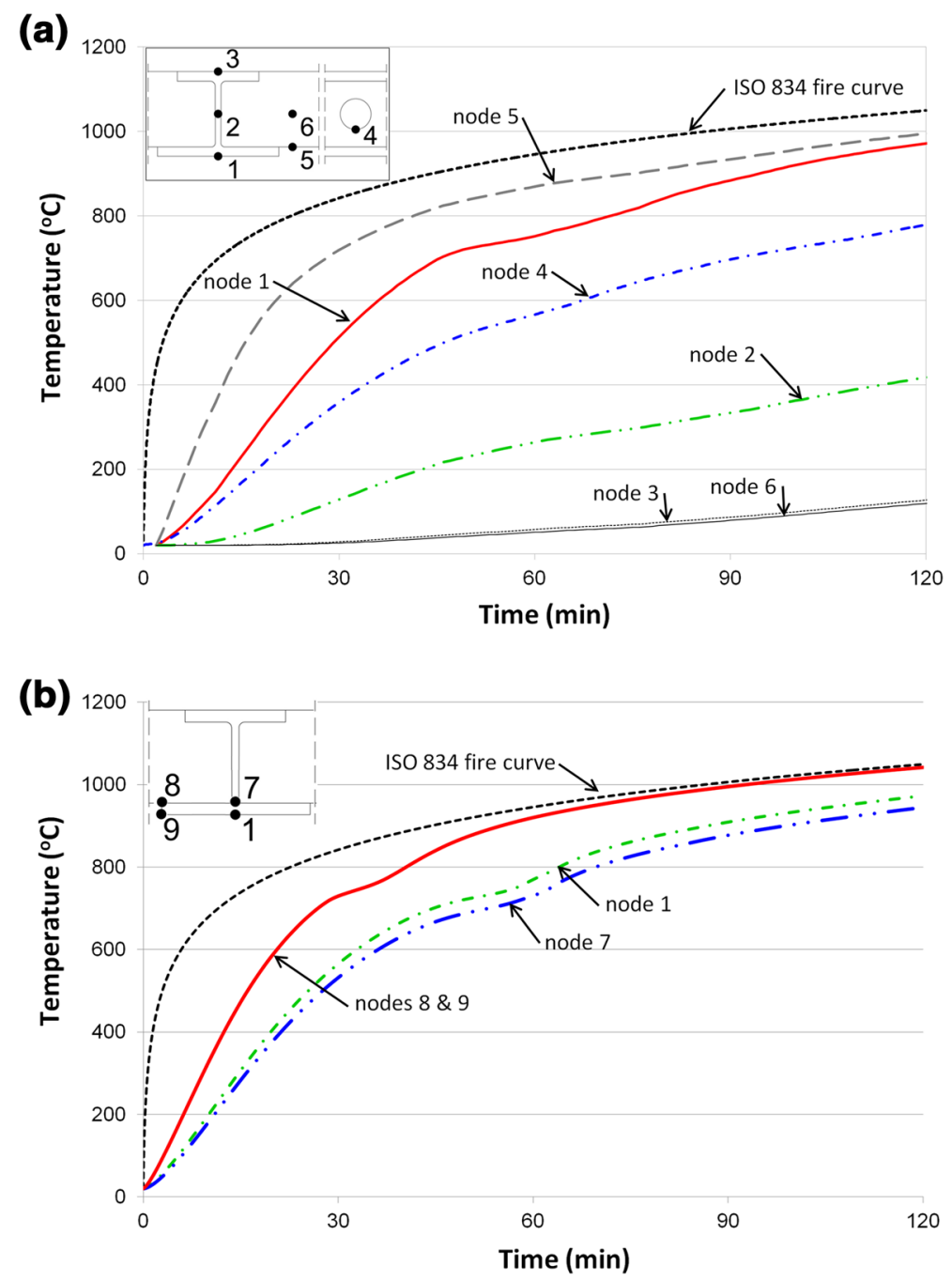

Figure 8. Temperature vs time for beam A, (a) at various positions and (b) at the bottom flange.

\subsection{Sensitivity Analysis}

In order to access the uncertainties of the used numerical model, a sensitivity analysis has been performed for the parameters presented in Table 2. In every analysis only one parameter according Table 2 was modified, so eight analyses for each beam were performed. The effect of these parameters has been presented in Figure 10 as error bars. The differences observed are minor and they do not affect the overall behaviour. 
(a)
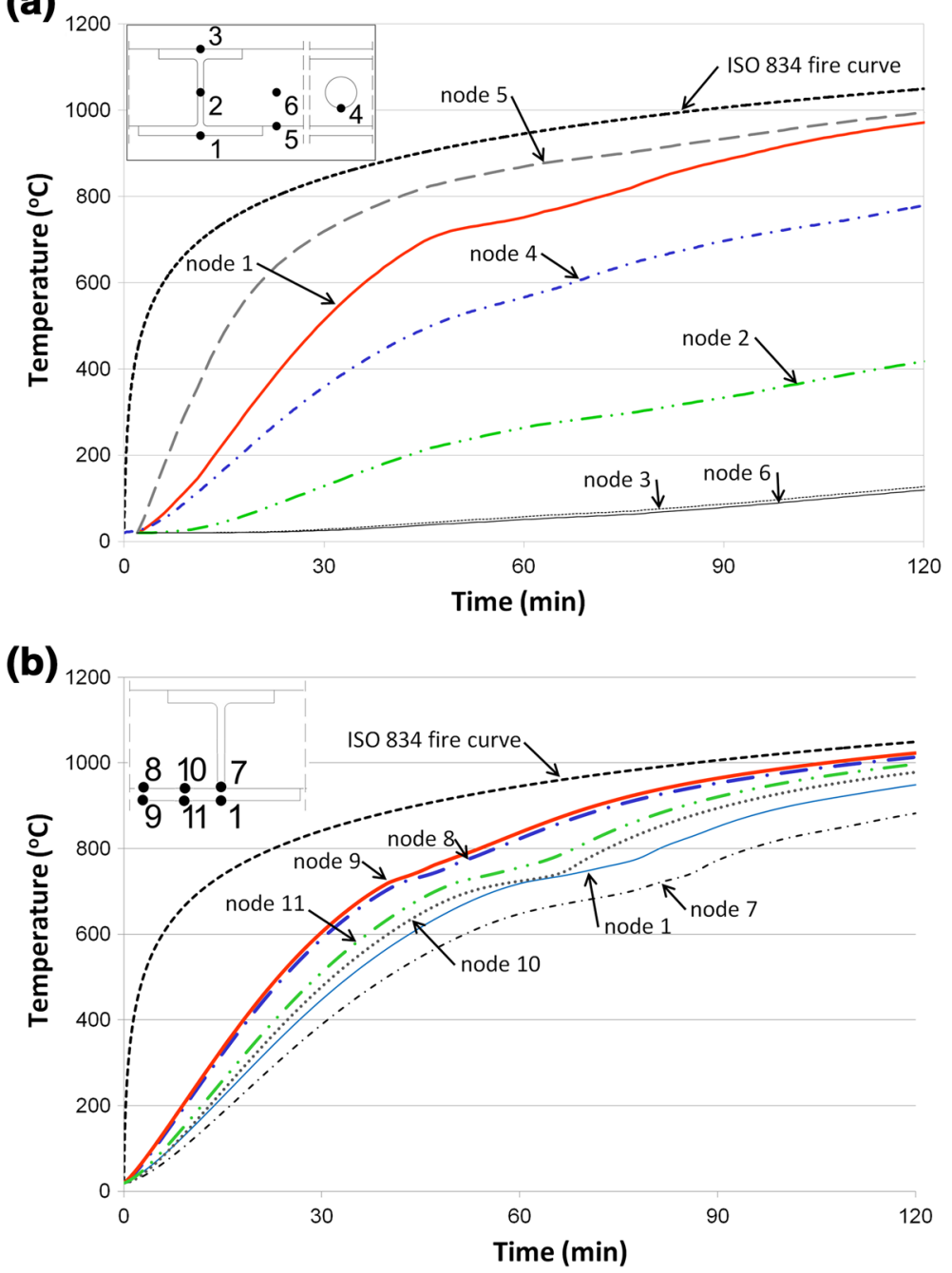

\section{Figure 9. Temperature vs time for beam B, (a) at various positions} and (b) at the bottom flange.

\section{Assessment of EC4-1-2 Procedure}

According to Westok calculations performed by CELLBEAM v.9.0 software [20], the critical temperatures according to EC4-1-2 [12] are $380^{\circ} \mathrm{C}$ (lower flange) and $566^{\circ} \mathrm{C}$ (web-post temperature) for beam $\mathrm{A}$, and $446^{\circ} \mathrm{C}$ (lower flange) and $604^{\circ} \mathrm{C}$ (web-post temperature) for beam B. As it was presented in Section 5.1, the lower flange temperature is always higher than the web temperature. Thus, the lower flange temperature governs the fire resistance of USFBs. Figure 11 realises the displacements, obtained from the presented FE analysis, as a function of the lower surface flange temperature (node 1). From Figure 11, it is evident that EC4-1-2 


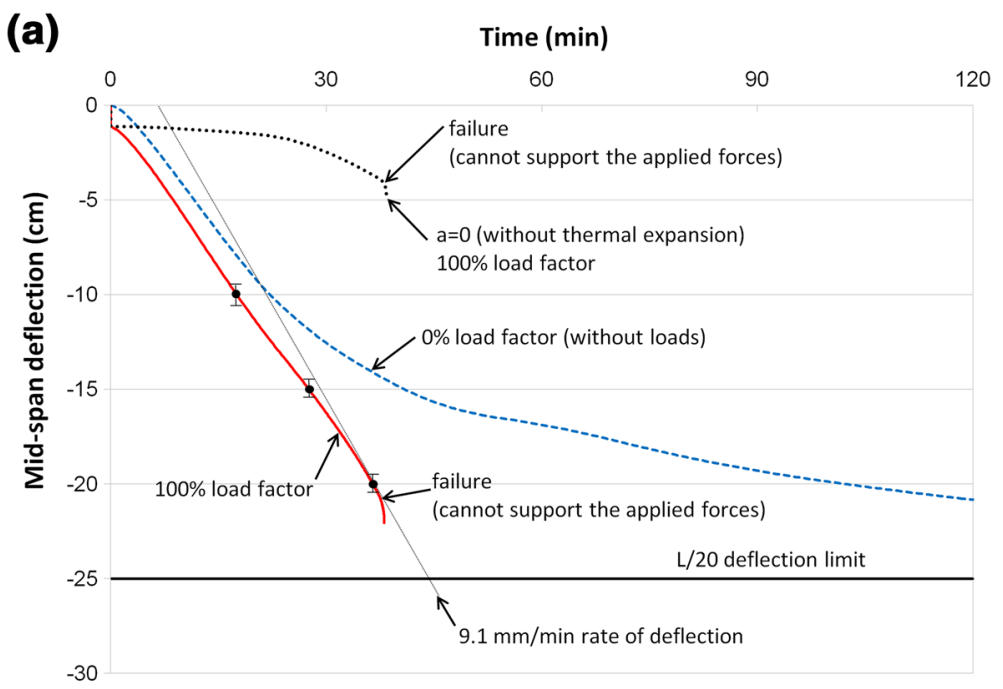

(b) Time (min)

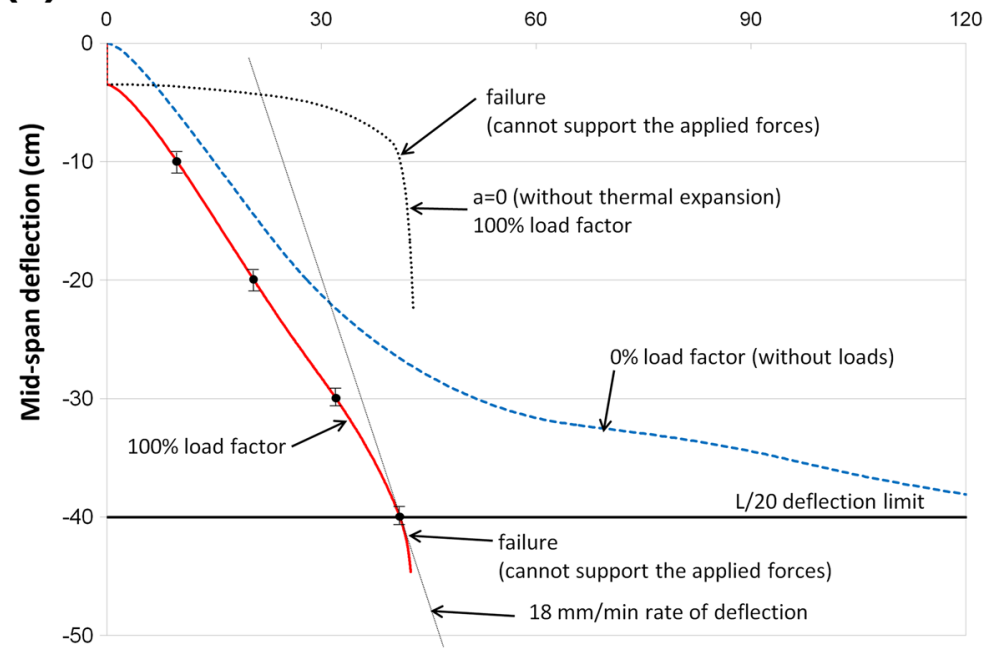

\section{Figure 10. Mid-span deflection versus exposure duration for (a) beam A, and (b) beam B.}

[12] gives satisfactory results; for both beams it gives rather conservative results, as beam A fails at $300^{\circ} \mathrm{C}$ higher temperature than EC4-1-2 predictions and beam $\mathrm{B}$ fails at almost $200^{\circ} \mathrm{C}$ higher temperature than the respected EC4-1-2 predictions. In any case, EC4-1-2, though not particularly accurate, seems to be on the side of safety. 


\section{Table 2}

Parameters Considered in the Sensitivity Analysis

\begin{tabular}{ll}
\hline Parameter & \multicolumn{1}{c}{ Value } \\
\hline Thermal expansion model & per EC4-1-2 [12] \\
& Constant value [12] \\
& per ASCE [22] \\
Element type & C3D8 \\
& C3D8i \\
Dilation angle for concrete & $15^{\circ}$ \\
& $30^{\circ}$ \\
& $55^{\circ}$ \\
\hline
\end{tabular}

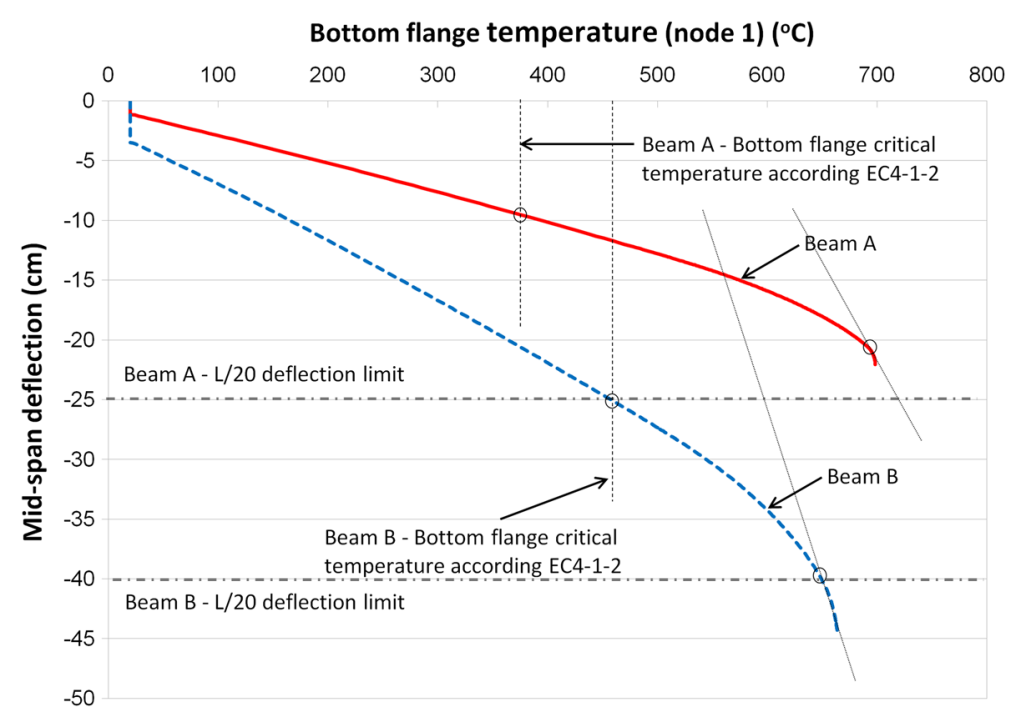

Figure 11. Displacement versus (node 1 ) bottom flange temperature.

\section{Moment and Shear Capacity}

\subsection{Effect of Fire on the Moment Capacity of USFBs}

When a steel-concrete composite beam is in equilibrium, the part of the steel section that is in tension produces a force equal to the resultant force of the concrete compressive stresses (to which are included the compressive stresses of the upper flange of the steel section and the reinforcement bars that nevertheless do not govern the behaviour as strains are limited by the concrete), as it appears in Figure $12 \mathrm{a}$. When the steel section has a hole in the web, the tensile force is produced from the bottom tee-section, and it is equal to its cross section area multiplied by the yield strength, is reduced by a corresponding safety factor (Figure 12b). When a non-uniform temperature profile, with temperatures generally larger than $400^{\circ} \mathrm{C}$, 


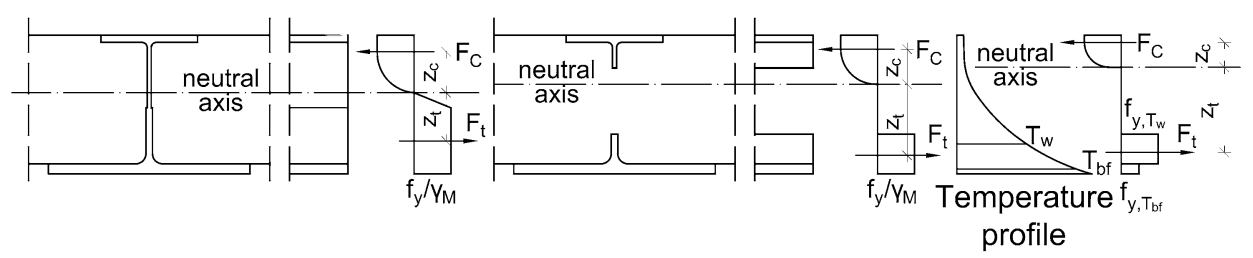

(a)

(b)

(c)

\section{Figure 12. Stress distribution of (a) a composite beam at normal temperafures, (b) when web penetrated, and (c) when web pene- trated and a non linear thermal profile applies.}

is applied on the section and particularly at the bottom tee-section, the yield strength is reduced. This mainly occurs at the lower flange which exhibits the highest temperatures and produces (proportionally to its cross section area and lever arm) the largest part of the moment capacity. The reduction of stresses at the lower flange cannot be partially covered by increasing the stresses at the web, as usually occurs in solid (non-perforated) sections [11], as the web is absent for the most part along the length of the beam. However, it is worth to be noted, that part of the tensile force reduction at the section is counterbalanced by the change of the material safety factor for fire design and the change in position of the neutral axis which increases the lever arm (Figure 12c).

As it can be seen in Figure 8a, at about 40 min (Figure 10a), when beam A fails, the mean temperature of the bottom Tee is about $555^{\circ} \mathrm{C}$, which corresponds to the yield strength with a reduction factor of 0.60 when the loads are reduced by $70 \%$ compared to the normal temperature design combination.

Respectively, regarding beam $\mathrm{B}$, failure results at about the same time (Figure $10 \mathrm{~b}$ ) and the mean temperature of the bottom Tee is $535^{\circ} \mathrm{C}$ (Figure $9 \mathrm{~b}$ ), which corresponds to the yield strength with a reduction factor of 0.67 .

Furthermore, improving the accuracy of the results, the average temperature of the bottom flange and bottom part of the web should be calculated separately as well as consider the reduction of yield strength for each one separately.

Using the standard fundamental conditions of equilibrium, the plastic analysis at the neutral axis can be calculated as:

$$
\sum_{i=1}^{n} \mathrm{~A}_{j} k_{y, \theta, i}\left(\frac{f_{y}}{\gamma_{\mathrm{M}, f i}}\right)+\sum_{j=1}^{m} \mathrm{~A}_{j} k_{c, \theta, j}\left(\frac{f_{c}}{\gamma_{\mathrm{M}, f i, c}}\right)=0
$$

where $A_{i}$ is the area of each fiber $i$ of steel at the area under tension, $k_{y, \theta, i}$ is the yield strength reduction factor of each steel fiber i for its (average) temperature $\theta$, $\mathrm{A}_{\mathrm{j}}$ is the area of each fiber $\mathrm{j}$ of concrete in compression and $\mathrm{k}_{\mathrm{c}, \theta, \mathrm{j}}$ is the reduction factor of concrete yield strength for each fiber $j$ with (average) temperature $\theta$. The $\mathrm{f}_{\mathrm{y}}$ and $\mathrm{f}_{\mathrm{c}}$ are the yield strengths of steel and concrete respectively and $\gamma_{\mathrm{M}, \mathrm{fi}}$ and $\gamma_{\mathrm{M}, \mathrm{fi}, \mathrm{c}}$ are the material safety factors for fire design for steel and concrete respectively. 
From Equation 3 it is clear that the reduction of the yield strength of steel due to temperature is resulting the reduction of the compression area $A_{c}$ and the change of the neutral axis position.

Therefore, the moment capacity can be calculated by:

$$
M_{f i, t, R D}=\sum_{i=1}^{v} A_{i} z_{i} k_{y, \theta, i}\left(\frac{f_{y}}{\gamma_{\mathrm{M}, f i}}\right)+\sum_{j=1}^{v} \mathrm{~A}_{j} z_{j} k_{c, \theta, j}\left(\frac{f_{c}}{\gamma_{\mathrm{M}, f i, c}}\right)
$$

where $z_{i}$ and $z_{j}$ are the distances of each fibre to the neutral axis.

As the steel area in tension is constant and equal to the area of the bottom Tee $\left(\mathrm{A}_{\mathrm{bTee}}\right)$, while it has an average temperature $\theta_{\mathrm{av}}$ and the temperature of concrete at the compression area is low and can be ignored, Equation 4 can be written as:

$$
M_{f i, t, R D}=A_{b, T e e} z_{t} k_{y, \theta a v}\left(\frac{f_{y}}{\gamma_{\mathrm{M}, f i}}\right)+A_{c} z_{c}\left(\frac{f_{c}}{\gamma_{M, f i, c}}\right)
$$

where $z_{t}$ and $z_{c}$ are the distances of the tensile and compressive force from the neutral axis.

As the USFBs are shallow and have web openings, the Equation 5 can be simplified by only considering the steel bottom tee-section; which is the most critical part in relation to strength reduction. Therefore, Equation 6 can be written as:

$$
M_{f i, t, R D}=A_{b, T e e}\left(z_{t}+z_{c}\right) k_{y, \theta a v}\left(\frac{f_{y}}{\gamma_{\mathrm{M}, f i}}\right)
$$

The steel in compression is not considered at the proposed plastic analysis. Its effect is minor because of the small dimensions of the upper flange in an asymmetric cross-section. For improved accuracy, Equation 3 can be modified and include both concrete and steel in compression.

\subsection{Effect of Fire on the Shear Capacity of USFBs}

According to [13] and [21] the shear capacity of USFBs is a combination of the following mechanisms:

- Bearing of the concrete inside the web opening;

- Friction between the concrete and both sides of the web due to the confining effect on the concrete;

- Additional shear resistance of the bar reinforcement over two shear planes.

As it results from Figures 7 and 8, the concrete temperatures (except in a strip of a few centimeters long) are low. Also, the reinforcement bar temperature is practically not affected by fire (node 4, Figure 8). The only effect that the fire seems to have is possibly the reduction of the confinement due to high temperatures of the lower flange. 
From the above numerical models, it is not possible to assess the effect of fire on the shear capacity, as no shear failure occurred. In addition, the effect of horizontal shear was not assessed as the slip between the concrete and steel was not allowed in the numerical models. Given the complexity of this mechanism, further investigation is deemed necessary.

\section{Conclusion}

The paper presents a numerical investigation of the USFB behaviour in fire when the lower flange is unprotected. A hypothetical fire test simulation of two typical USFBs are demonstrated. The basic difference between the USFBs and other flooring systems is that the web is penetrated and so it is unable to produce significant moment capacity when the hot lower flange cannot provide sufficient tensile force. The difference between penetrated and non-penetrated web beams depends on the web thickness. The beams without web penetration have shown increased fire resistance, between $5 \mathrm{~min}$ and $15 \mathrm{~min}$, compared with the penetrated web USFBs. If the fire resistance of USFBs is compared with those of unprotected beams of same or similar cross-section thickness, the USFBs have considerably improved fire resistance as the unprotected beams may not exceed the $15 \mathrm{~min}$.

In general, EC4-1-2 provides safe results for the fire resistance of such specimens; however USFB models with different slenderness and opening sizes need to be examined. USFBs with unprotected lower flange have a fire resistance of R40 and, as it was demonstrated, that is affected by the load factor and the deflection (thermal bowing). In order to improve the fire resistance of USFBs, the lower flange must be protected so that bowing is avoided and temperatures are reduced. Alternatively, a lower load factor might be used (or a combination of the above).

Recommendations drawn by this study emphasise that a special attention should be given to conduct fire tests for extreme designs of USFBs with in-situ as well as pre-cast slabs, in order to assess the extent of use of the current regulated specifications. Such fire tests can also be used to validate further detailed computational models simulating slim floor steel-concrete flooring systems. Moreover, it is suggested that the shear connection systems should be assessed regarding the effect of fire, and elevated temperature push-out tests should be conducted.

A series of experimental fire tests are prepared to be conducted at the University of Ulster with those types of beams including all the structural details after the award of funding from the VCRS (Vice Chancellor Research Scholarship award for a PhD student). One of the integrated beams will have a solid web in order to be used in the investigation and documentation of temperature profiles through the unprotected composite integrated beams. The experimental data will provide the information to understand the strength loss before the failure and mechanisms of the failure modes, referential data for the calibration of the finite element models, and extended range of results; a solid basis for the definition of design rules and constructional details. 


\section{Acknowledgments}

The authors of this work would like to thank ASD Westok 1td. and ASD Metal Services for the technical support in the development of the final design for the examined USFB sections as well as for the supply of steel perforated specimens for the subsequent experimental works. It is expected that the results from this research study will be incorporated in Westok's design software for USFBs (USFB-AutoMate) developed and certified by the Steel Construction Institute (SCI), updating the inherited fire design resistance of steel-concrete composite USFB sections. Further, the authors would like to accredit the University of Manchester for their support (covering Article Processing Charge).

\section{Open Access}

This article is distributed under the terms of the Creative Commons Attribution 4.0 International License (http://creativecommons.org/licenses/by/4.0/), which permits unrestricted use, distribution, and reproduction in any medium, provided you give appropriate credit to the original author(s) and the source, provide a link to the Creative Commons license, and indicate if changes were made.

\section{References}

1. ASD Metal Services, Westok, Ultra Shallow Floor Beams, http://www.kloecknermetalsuk.com/kloecknerwestok/usfb/. Accessed 21 Mar 2016

2. Maraveas C, Swailes T, Wang YC (2012) A detailed methodology for the finite element analysis of asymmetric slim floor beams in fire. Steel Constr 5(3):191-198

3. Maraveas C, Wang YC, Swailes T (2014) Fire resistance of 19th century fireproof flooring systems: a sensitivity analysis. Constr Build Mater 55:69-81

4. Maraveas C (2014) Numerical analysis of DELTA composite beams in fire. In: 7th European conference on steel and composite structures-EUROSTEEL

5. Bailey CG (1999) The behaviour of asymmetric slim floor steel beams in fire. J Constr Steel Res 50:235-257

6. Newman GM (1995) Fire resistance of slim floor beams. J Constr Steel Res 33:87-100

7. Ma Z, Mäkeläinen P (2000) Behaviour of composite slim floor structures in fire. J Struct Eng ASCE 126(7):830-837

8. Mäkeläinen P, Ma Z (2000) Fire resistance of composite slim floor beams. J Constr Steel Res 54:345-363

9. Ellobody E (2011) Nonlinear behaviour of unprotected composite slim floor steel beams exposed to different fire conditions. Thin-Walled Struct 49:762-771

10. Both C, Fellinger JHH, Twilt L (1997) Shallow floor construction with deep composite deck: from fire tests to simple calculation rules. Heron 42(3):145-158

11. Maraveas C, Wang YC, Swailes T (2016) Moment capacity of cast iron beams exposed to fire. In: Proceedings of ICE: structures and buildings. doi:10.1680/jstbu.15.00120

12. EN 1994-1-2 (2005) Eurocode4 design of composite steel and concrete structures-part 1-1: design for fire, CEN, Brussels 
13. Tsavdaridis KD, D'Mello C, Huo BY (2013) Experimental and computational study of vertical shear behaviour of partially encased perforated steel beams. J Eng Struct $56: 805-822$

14. Yu Huo B, D'Mello C, Tsavdaridis KD (2010) Experimental and analytical study of push-out shear tests in ultra shallow floor beams. In: 34th international association for bridge and structural engineering (IABSE) symposium, Venice, Italy, pp 31-38

15. Tsavdaridis KD, Giaralis A (2011) Derivation of dynamic properties of steel perforated ultra shallow floor beams (USFB) via finite element modal analysis and experimental verification. The 7th national conference on steel structures, Volos, Greece, vol 2, pp 321-329

16. Tsavdaridis KD, D'Mello C, Hawes M (2009) Experimental study of ultra shallow floor beams (USFB) with perforated steel sections. Nordic Steel Construction Conference 2009, NSCC2009. 2-4 September 2009, Malmö, Sweden, Reference no. 128, pp 312-319

17. EN 1991 (2002) Eurocode 1-actions on structures - part 1-2: general actions - actions on structures exposed to fire. CEN Brussels

18. ISO 834-1 (1999) Fire-resistance tests - elements of building construction-part 1: general requirements. ISO, Switzerland

19. Abaqus v6.11 (2012) User manual, Simulia

20. Cellbeam v.9.0.0 (2013) User manual, westok/SCI

21. Enchanced design of ultra shallow floor beams, New Steel Construction, June 2011, pp $30-31$

22. Kodur V, Dwaikat M, Fike R (2010) High-temperature properties of steel for fire resistance modeling of structures. J Mater Civ Eng ASCE 22(5):423-434 